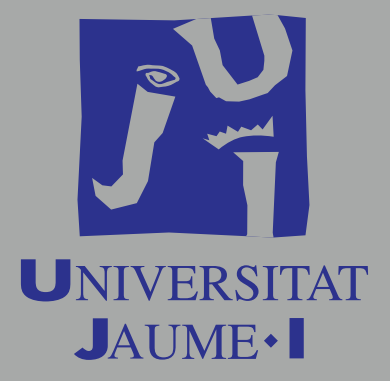

\title{
Ètica o crisi. La distribució de la responsabilitat
}

Domingo García Marzá

\section{Lliçó inaugural del curs 2012/13}




\title{
LLIÇó INAUGURAL DEL CURS 2012-2013
}

\section{ÈTICA O CRISI. LA DISTRIBUCIÓ DE LA RESPONSABILITAT}

\author{
Domingo García Marzá \\ Catedràtic d'Ètica \\ Director del Departament de Filosofia i Sociologia \\ Universitat Jaume I
}

Castelló de la Plana, setembre de 2012 
Edita: Servei de Comunicació i Publicacions

Universitat Jaume I

Edifici Rectorat i serveis centrals

Campus del Riu Sec

12071 Castelló de la Plana

www.uji.es·comunicacio@uji.es

Tel. 964728833

Dipòsit legal: CS 326-2012

http://dx.doi.org/10.6035/Llico.2012.2013

Imprimeix: Innovació Digital Castelló, s.l.u. 


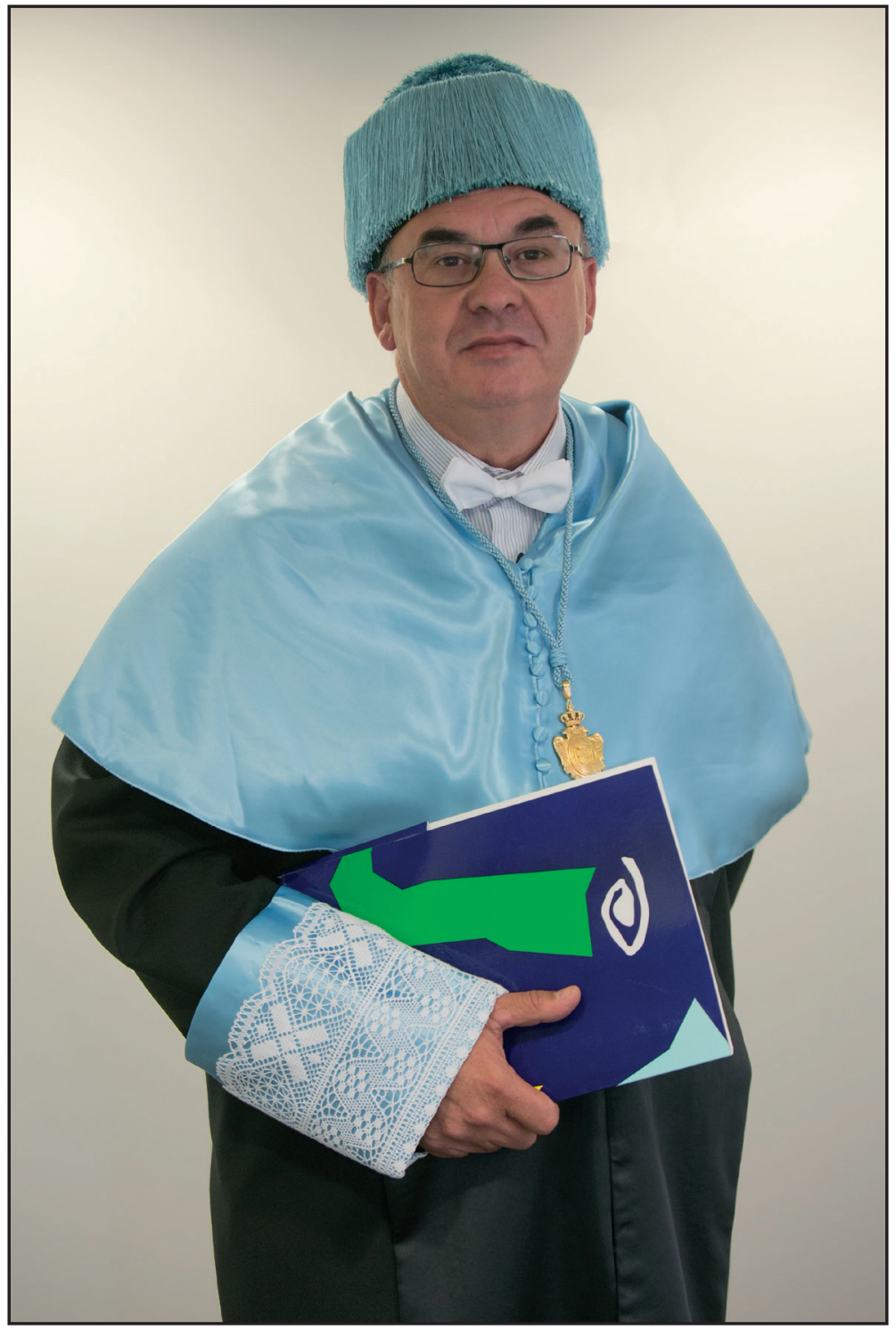




\section{ÈTICA O CRISI. LA DISTRIBUCIÓ DE LA RESPONSABILITAT}

Excel-lentíssimes autoritats, companyes i companys, amigues i amics.

Vull donar les gràcies, en primer lloc, al nostre rector i al seu equip per la confiança mostrada d'encarregar-me aquesta lliçó inaugural.

L'objectiu d'aquesta breu lliçó és plantejar una reflexió sobre la crisi des d'una perspectiva ètica, que és, per definició, una perspectiva crítica. El meu interès és destacar l'important paper de les institucions de la societat civil i, dins d'aquestes de l'ètica, presentant les línees bàsiques d'una ètica per a les institucions.

El punt de partida per a aquesta reflexió no pot ser altre que la situació actual de crisi. Una crisi econòmica i social que guarda molta relació amb una crisi moral, no en el sentit d'un buit de valors, sinó en el significat més bàsic d'una desmoralització, d'una falta de valor i força per a transformar la realitat. En aquesta direcció, presentaré algunes idees per a una recuperació del poder moral inherent a les persones i a les institucions, dins del que denominaré una moralització de la societat civil.

Els qui treballem en ètica no som moralistes. No espereu, per tant, un sermó sobre allò que està bé o malament, sobre el que hem de fer o deixar de fer. Part del títol d'aquesta lliçó l'he agafat d'una pintada que hi ha a un pont de l'autovia a l'entrada d'Almenara, a l'entrar a la nostra província: «Ètica o crisie»». Ens planteja una elecció; més bé, una disjuntiva. 
La meua intenció és analitzar aquesta expressió com a part d'un saber moral que tots tenim. A l'igual que els físics estudien la gravetat com un fet natural, els qui investiguem en ètica estudiem el llenguatge moral i el paper social que desempenya. No tenim cap accés privilegiat a la veritat, ni som millors o pitjors professionals que la resta d'investigadors i investigadores pel fet d'estudiar l'àmbit moral. La diferència amb les altres disciplines científiques és que la realitat que estudiem depèn al mateix temps de la nostra mirada i de la nostra intervenció. Mentre que la gravetat no canviarà amb els resultats de la física, la societat en què vivim depèn de què entenguem per justícia, per igualtat, per llibertat, per drets humans, etc. Com deia Aristòtil, l'ètica és un saber pràctic que vol comprendre la realitat per a canviar-la, és una reflexió per a l'acció.

Per a aconseguir l'objectiu proposat, faré tres passos:

- En primer lloc, explicaré en què consisteix aquest saber moral del qual se n'ocupa l'ètica, com funciona i quina relació té amb la responsabilitat.

- En segon lloc, analitzaré la importància de les institucions com a potenciadores de l'acció moral individual, proposant un esquema de doble distribució de la responsabilitat.

- Per últim, presentaré algunes idees per a repensar les institucions des de l'ètica, és a dir, de l'ètica com a part fonamental del disseny institucional.

\section{L'ÈTICA EN ACCIÓ: ELS RECURSOS MORALS}

La paraula crisi arriba a les ciències socials des de l'àmbit de la medicina i la biologia. Un organisme està en crisi quan té més problemes que possibilitats o recursos per a resoldre'ls i, per tant, corre el perill de desaparèixer. Això és el que està passant amb les nostres democràcies i amb el sentit de moltes de les institucions que fins ara sostenien la nostra manera d'entendre i de viure la vida en comú. Ètica o crisi. Per què l'ètica és una alternativa a la crisie De què parlem quan parlem d'ètica?

Una manera de visualitzar el fet moral és parlar de la moralitat com un saber que tenim, com un coneixement que s'expressa en el llenguatge moral, en els sentiments, valors i normes que el llenguatge transmet. Freqüentment diem que és indecent premiar els corruptes amb pensions milionàries; que les llistes d'espera són indignants; que és injust que els qui no puguen pagar no arriben a la universitat; que és inhumà deixar de prestar atenció sanitària a les persones; que és immoral que els qui menys culpa tenen paguen la crisi, etc. 
Darrere d'aquestes expressions trobem un saber moral que ens diu, quasi sempre de manera implícita, com comportar-nos i, per tant, què podem esperar els uns dels altres, quins drets i deures tenim com a persones, també com a professionals, amics, socis, clients, etc. Un saber que ens permet, en suma, conèixer allò que està bé o malament, que és just 0 injust. La característica bàsica d'aquest conjunt de valors i normes que defineix la moralitat és la universalitat: si una decisió, acció o institució és moral, ho és perquè afecta a tots i a totes per igual.

La teoria ètica estudia com es conforma aquest saber, quines són les condicions que fan falta per a poder respondre d'aquesta pretensió d'universalitat. No inventa aquestes condicions, més bé les trau d'aquest saber compartit. Entre nosaltres, la professora Adela Cortina ha fet aquest esforç i ens parla d'una ètica cívica, d'una ètica mínima que ens diu què és allò necessari per a definir i defensar la dignitat, per a construir una societat justa en les societats globals actuals. Ens proposa una fórmula per a combinar aquest universalisme moral i el pluralisme cultural que defineix les nostres societats: exigir el compliment d'un mínim moral de justícia i respectar activament els màxims de felicitat de cada cultura.

En l'actualitat, la Declaració Universal dels Drets Humans és la plasmació més assolida fins ara d'aquests mínims morals que defineixen la dignitat. Amb la terminologia d'Ortega, representen l'altura moral del nostre temps.

Des d'aquesta comprensió de l'àmbit moral podem entendre millor la relació entre ètica i responsabilitat i, al mateix temps, trencar alguns malentesos que encara avui llastren la utilització del concepte responsabilitat. Els treballs del professor Karl-Otto Apel ens permeten distingir tres significats diferents de responsabilitat.

En primer lloc, i potser el significat més comú de responsabilitat és el que ens porta a conceptes com dany i culpa. D'aquesta manera, responsabilitat té a veure sempre amb un obrar equivocat, fins i tot amb accions punibles. Sempre pareix que fem les coses malament i la responsabilitat vindria a ser la reparació del dany causat. Es tracta d'una visió negativa, reactiva, que explica molt bé perquè, encara avui, a molta gent no li agrada el concepte. Ara bé, podríem objectar, també som responsables de les coses ben fetes.

En segon Iloc, apareix un concepte utilitarista de responsabilitat, vinculat al càlcul de resultats. La responsabilitat és ara un concepte causal: una persona o institució és responsable d'alguna cosa quan és la causa, motiu o agent primari de la mateixa. No és difícil veure com en contextos complexos com els actuals, aquesta responsabilitat es difumina i al final no mai saps qui n'és responsable, ni quan, ni com. D'aquesta manera, la validesa moral es dilueix en un càlcul de 
conseqüències, on sempre acaba per comptar allò que diu i vol qui més poder té per a definir què és allò que compta.

Per últim, tenim un concepte de responsabilitat que la nostra tradició filosòfica s'ha encarregat d'estudiar, com ara Ortega, Zubiri i Aranguren. Responsabilitat vinculada a la llibertat, al fet existencial bàsic que som Iranimals de possibilitats"l. Mentre que els animals tenen la conducta ajustada pels instints, els éssers humans hem d'ajustar la nostra relació amb els altres des de la nostra Ilibertat. Ajustar i justificar tenen la mateixa arrel. Responsabilitat deriva de respondre, de defensar una qüestió en públic, de justificar una acció.

Ser responsable significa ser capaç de donar raó d'allò que hem fet o deixat de fer. Som responsables quan tenim diferents alternatives d'acció i ens decidim per una d'aquestes, de la qual hem de respondre. No demanem responsabilitat quan no podem elegir, quan no som lliures. Front a les responsabilitats específiques que tenim com a membres d'una família, com a professionals, com a ciutadans, etc., la responsabilitat moral constitueix la base de totes, atès que es refereix als drets $i$ obligacions que tenim com a persones i davant de les persones.

En resum, responsabilitat és la capacitat que tenim de respondre de com hem utilitzat el saber moral que tenim, si hem actuat o no com els altres esperaven, si hem estat a l'altura. Per a dir-ho breu, la responsabilitat és l'ètica en funcionament.

Potser ens vindria bé un parell d'exemples de les ètiques aplicades que, com sabeu, treballem a la nostra Universitat des dels inicis. Ens permetran entendre millor aquesta relació entre ètica i responsabilitat $i$, per tant, el funcionament d'aquest saber moral.

Quan, com a pacients, anem a l'hospital ja sabem, abans d'entrar-hi, sense haver estudiat ètica, què podem esperar del professional sanitari i del mateix hospital. Aquest saber està conformat per un conjunt d'expectatives pressuposades i assumides: esperem que es preocupen de la nostra salut; que ens curen i ens cuiden; que respecten la nostra opinió i la nostra voluntat; que no ens discriminen, que els recursos estiguen a l'abast de tots per igual, etc. L'objectiu de la bioètica és estudiar aquest saber ja existent i plasmar-lo en principis d'actuació, uns principis que després recolliran els codis, i les lleis positivaran. Quan les expectatives que conformen aquest saber no es compleixen, és quan ens sentim humiliats i menyspreats, i perdem la confiança dipositada en el professional sanitari o en l'hospital. Si tenim l'oportunitat, buscarem un altre hospital o canviarem de metge.

El mateix podem dir dins de l'àmbit econòmic. En paraules d'Amartya Sen, premi Nobel d'Economia, és difícil no veure l'important paper que té l'ètica empresarial tant en els contractes i negociacions, com en la producció, l'intercanvi i 
la distribució. És d'idiotes, d'idiotes racionals, com diu el mateix Sen, pensar que l'egoisme i l'interès propi fan funcionar per si mateixos els mercats. Sense aquest saber moral, sense la honestedat que comporta respectar els contractes; sense la cooperació i col/laboració necessàries per a la producció; sense la credibilitat del producte o marca, etc., no hi ha confiança. I sense confiança no hi ha mercat, només hi ha selva. Com conclou Sen, l'ètica empresarial es pot considerar com un dels actius productius més importants que una economia i una societat disposen.

Una simple anècdota em permetrà destacar la dificultat d'entendre aquesta concepció positiva de la responsabilitat. Quan vam començar a treballar en l'ètica empresarial, allà pels anys noranta, vaig fer la primera entrevista a un empresari nostre. Quan varem entrar al despatx i li diguerem que veníem a parlar d'ètica empresarial va exclamar esglaiat: "El que faltava!". Parlar d'ètica era parlar de allò que no fem bé, reconèixer que s'han fet les coses malament $i$, al final, acabar pagant més. Un passiu, en definitiva.

Però avui les coses han canviat i molt. Afortunadament, tenim dades indiscutibles de com les empreses responsables s'han enfrontat millor a la crisi i com gràcies a una gestió ètica i responsable són avui bons exemples de que el benefici econòmic no està renyit amb el benefici social.

Que el saber moral no es justifique per la utilitat, no vol dir que no tinga cap utilitat, com acabem de comprovar en els exemples. La moralitat es fonamenta en el respecte a la dignitat de les persones $i$ en utilitzar aquest saber podem relacionar-nos amb els altres, establir actuacions conjuntes i crear espais per a organitzar-nos. El saber moral no és cap adornament, ni tampoc un lubricant per a la sempre difícil maquinària social. En les ètiques aplicades entenem l'ètica com un recurs, com una capacitat sense la qual cap pràctica social és possible.

Ara bé, els recursos morals són un tipus especial de recursos. En primer lloc, només funcionen quan seguim els valors i normes morals, no quan actuem per estratègia, en el sentit que l'lètica neteja més blancll. En segon lloc, mentre que la resta de recursos, financers, energètics, materials, etc., s'exhaureixen com més s'utilitzen, els recursos morals funcionen a l'inrevés: com més els utilitzem, més en tenim i, si no els utilitzem, desapareixen. Penseu per un instant en la confiança o en la reputació com a resultat de la utilització d'aquests recursos morals i sabreu per què la crisi actual guarda tanta relació amb l'ètica.

La pintada "Ėtica o crisi» es pot interpretar des de la necessitat de recuperar aquests recursos derivats de la nostra capacitat d'actuar de manera justa i correcta amb els altres, d'assumir compromisos, de respondre d'allò s'espera de nosaltres; d'estar a l'altura, en definitiva. Oblidant aquesta capacitat, hem renunciat al mecanisme bàsic que permet la coordinació i la colllaboració i hem quedat impotents per a afrontar gran part dels nostres problemes, com ara l'economia i la política. 
Quan era xicotet i estava malalt i feble, recorde que ma mare em deia: "Aquest xiquet no té virtut». El llenguatge quotidià ens porta al nucli d'aquest saber moral: "No tindre virtut» vol dir no tindre força; "lestar baix de moral») vol dir no tindre energia per a canviar les coses; "tindre la moral per terra" vol dir no tindre ja vitalitat per a conduir la nostra vida individual o collectiva. La crisi entra per la porta oberta que deixa aquesta desmoralització. Moralitzar la societat no vol dir res més que recuperar aquest poder. Una altra qüestió és com fer-ho. És en aquest punt on entren les institucions.

\section{LA PERSPECTIVA INSTITUCIONALISTA O EL PODER DE LA SOCIETAT CIVIL}

Abans d'entrar en el paper de les institucions m'agradaria tornar per uns moments al nostre punt de partida. Hem relacionat la crisi amb la desmoralització, amb la falta de virtut i força per a afrontar-ne els problemes. Si no diem res més, pareix que la causa de la crisi radica en aquest desànim, i es carrega, d'aquesta manera, a les espatlles dels individus la culpa del que passa. Per exemple, com si la crisi fóra només un estat psicològic que es pot resoldre amb exercicis mentals, amb un parell de píndoles o amb campanyes publicitàries com "Entre tots ho arreglem». Com no podem canviar una realitat clarament injusta, canviem la nostra ment perquè s'hi acostume. Mai no he vist manipulació més burda i més cruel, que la que acaba per responsabilitzar de la crisi a les víctimes.

La desmoralització actual no ha estat sempre igual, no és un fet natural. És un constructe social fruit de la conjunció entre una cultura individualista on triomfa l'idiota racional que pensa que no deu res a ningú, i un procés continuat de degeneració de la vida pública, una permanent vulneració de les expectatives dipositades en les institucions i en les autoritats. La insatisfacció, el pessimisme, la frustració, la desafecció i un llarg etcètera són les conseqüències d'una situació on la corrupció i el cinisme han estat normals durant massa temps.

Quan preguntem per la responsabilitat davant la crisi hem d'oblidar-nos de la relació lineal causa-efecte i pensar en processos dinàmics; perquè, en aquest món social, les persones som tant actors com productes d'una determinada realitat social. Això vol dir que la crisi i la desmoralització s'alimenten una de l'altra, i formen un cercle viciós. Per a trencar aquest cercle hem de recuperar la nostra capacitat d'actuar moralment i aquesta és una tasca que no podem fer-hi sols.

D'una banda és evident que som les persones, com a individus, els qui tenim l'última paraula a l'hora de decidir si actuem d'acord amb allò que s'espera 
nosaltres, és a dir, si utilitzem o no el saber moral que compartim. La voluntat té la base última en l'actuació moral, també com a professionals. De fet, l'ètica professional, la responsabilitat i el compromís públic dels professionals, és una de les poques esperances que ens queden per a fer front a la injustícia que representa l'actual abandonament sistemàtic dels drets socials i econòmics. Això sí, cadascú ha de respondre del seu espai de llibertat. La responsabilitat és directament proporcional al poder.

Però, del voler al poder hi ha una gran distància. Moltes vegades, un abisme insalvable. Tots els que estem avui ací, dalt o baix, estem farts de trobar-nos en situacions on hem hagut de confirmar la nostra impotència per a canviar les coses. Hem comprovat que potser tenim voluntat, però no el suficient poder per a aconseguir els nostres objectius. Si ja passa en els projectes vitals, què direm de la corrupció política, de la deriva clientelista dels partits polítics o de la desigualtat $i$ injustícia que ens envolta?

Ens cal més poder per a canviar la realitat des del nostre saber moral, però també espais on utilitzar aquests recursos. Ens trobem en moltes situacions en les quals no és possible aplicar els recursos morals perquè anirien contra tota prudència, on no tenim més remei que actuar estratègicament. En el nostre idioma tenim un joc de paraules per a expressar intuïtivament aquesta situació: "Idues vegades bo...ll. El saber moral, com diu de nou Adela Cortina, no demana ni màrtirs ni herois. Demana persones amb voluntat de fer bé les coses i espais de confiança per a realitzar-les.

Aquestes situacions, i moltes més on ara no tenim temps d'entrar-hi, ens porten a plantejar-nos la necessitat d'una distribució de la responsabilitat. La meva tesi és que hem de donar-li més importància al pensar i actuar institucional per a potenciar els recursos morals i, en el cas que ens ocupa, eixir de la crisi. Dit d'una altra manera, hem de plantejar-nos una distribució de la responsabilitat entre les persones, d'una banda i les institucions, d'una altra. Però, què son les institucions?, quin paper tenen en l'aplicació d'aquest saber moral?

Una primera aproximació a l'existència dels actors institucionals és, de nou, el nostre llenguatge quotidià. Les exigències i expectatives que el llenguatge moral s'encarrega de transmetre no es redueixen a la conducta individual. Contínuament fem judicis i valoracions morals per a referir-nos a les institucions i organitzacions i som capaços de separar la responsabilitat individual de la institucional. Quan diem que el sistema judicial no és just, que tal empresa és immoral, que és indecent la situació de tal hospital, que no hi ha dret que la universitat se semble cada vegada més a un mercat, etc., utilitzem aquest saber moral.

Des del moment en què les institucions com ara la família, el govern, l'empresa, la universitat, l'església, els partits polítics, els sindicats, les cambres de 
comerç, les fundacions, associacions i organitzacions, etc., tenen poder són agents de justícia i són responsables com a institucions.

Per tres motius bàsics:

En primer lloc, perquè tenen una estructura, un sistema de regles que fan que les decisions no es puguen reduir ni als individus ni als grups que les componen. En segon Iloc, perquè tenen uns valors i una cultura corporativa que defineixen una personalitat pròpia, un caràcter o manera específica de pensar i ser. Per últim, perquè tenen un poder, una capacitat de fer i desfer, molt superior a la dels individus. En resum, tenen també un espai de llibertat des del qual poden fer les coses d'una manera o d'una altra. Un poder i una llibertat dels quals han de respondre davant la societat si volen mantindre'n la confiança. És a dir, si volen sobreviure.

És difícil definir què és una institució, perquè moltes vegades està en funció de l'enfocament teòric que fem. Però, crec que entendrem de què parlem si les comprenem com a acords socials estables, instituïts per a la solució de problemes socials bàsics com ara la convivència, la creació de valors, la salut, l'educació, etc. Els acords socials es concreten en un sistema de regles que defineix com comportar-nos i al qual hem d'ajustar-hi la nostra conducta per a assolir el bé social buscat. Aquestes regles s'encarreguen de proporcionar, tant els hàbits de pensar o d'actuar, com de reprimir o habilitar les decisions i accions.

Per aquest motiu, quan preguntem per la responsabilitat de la situació actual, en el sentit de respondre per aquesta, apareix un primer eix de distribució entre les persones, d'una banda i les institucions, d'una altra. El marc institucional limita o potencia l'acció individual i, per tant, condiciona la responsabilitat dels individus. Si, com diu Karl-Otto Apel, la responsabilitat individual depèn del marc públic de les institucions, aquesta responsabilitat ha de ser compartida. Suspendre la reflexió en l'àmbit individual, com ja ens avisà Hegel, vol dir sobrecarregar els individus amb una responsabilitat excessiva, perquè el resultat desitjat no sempre està en funció de la nostra voluntat.

Però, el poder institucional no és cap poder natural. Són acords socials que necessiten l'acceptació i el suport diari de la societat, és a dir, requereixen legitimitat. Parlem de legitimitat per a referir-nos a la creença en la justificació del poder, en la justícia d'aquest, com deixen ben clar autors com ara John Rawls o Jürgen Habermas. Les institucions es diferencien pel bé social que proporcionen, però és el consentiment de tots els afectats i implicats allò que en defineix la moralitat. Només l'acord de tots sobre si s'aconsegueix o no el bé social buscat, sobre l'eficàcia assolida, pot justificar la distribució asimètrica de càrregues i beneficis que suposa tota institució. Sense aquest consens, moltes vegades implícit, les institucions perden credibilitat i confiança progressivament i, al final, desapareixen. 
Les institucions són estables per definició, però també són vulnerables. Per això, és millor pensar les institucions com un procés d'aprenentatge on canviem el disseny institucional d'acord a com afrontem nous problemes. Economistes com Douglass Cecil North veuen en el canvi institucional l'única possibilitat per a transformar i millorar les societats i ens proposen distingir entre institucions, com a definició del marc de sentit, $i$ les organitzacions com a concrecions d'aquest marc de regles i valors, com a instàncies de realització. La universitat és una institució; la Universitat Jaume I, una organització. D'aquesta manera, podem saber si les organitzacions s'apropen o s'allunyen de la idea que les justifica. Una distància que es mesura pel grau de confiança o desconfiança que generen.

$\mathrm{Si}$ ens centrem ara en el tipus de poder que tenen les institucions, i entenem per poder la capacitat de definir i satisfer interessos, ens trobem amb un nou eix en la distribució de la responsabilitat. Normalment, quan parlem d'institucions, ve a la ment el govern, les cambres legislatives, el sistema judicial, etc. És a dir, sempre institucions de l'Estat. Però, si ens fem un parell de preguntes, vorem de seguida que amb aquesta delimitació hi ha actors institucionals que no apareixen, que es queden a l'ombra. No tenen poder, i per tant responsabilitat, les empreses, per exemple, els mercats financer o els bancs?, tampoc les universitats, per exemple, en el retorn social de la recerca i no en la formació d'una, si em permeteu el neologisme, isicràcia?, no tenen capacitat d'influir les organitzacions no governamentals com ara Greenpeace o Amnistia Internacional?, no tenen poder les esglésies en la formació de sentit i en la influència en els governs?, etc.

Durant molt de temps, tant en el terreny acadèmic com en la pràctica diària, hem confós la responsabilitat pública amb la responsabilitat estatal. Un dels nostres majors errors ha estat pensar que l'Estat i les institucions d'aquest eren els únics responsables d'allò públic. Per a dir-ho més clar, hem deixat que els polítics agafen, cada vegada més, espais d'acció, i s'introdüisquen en totes les esferes socials i econòmiques. De fet, en comptes d'una moralització de la vida pública, estructurada al voltant de la responsabilitat individual i institucional, ara tenim una politització de la vida pública, estructurada per la lògica dels partits polítics, que poc o no res té a veure amb el compromís públic. La política és necessària per a gestionar allò públic, però avui sabem que la democràcia, com a manera de conviure, és massa important per a deixar-la en mans dels polítics.

Per això, el nou institucionalisme ha dirigit la mirada cap a la recuperació de les institucions de la societat civil. Si volem un canvi, si volem superar la desmoralització, hem de pensar en una segona distribució de la responsabilitat, en un nou eix de distribució. Aquesta vegada entre l'Estat i la societat civil. Hem d'anar a buscar els llocs institucionals on es produeix i es reprodueix el poder. L'aposta és per una democràcia de doble via, per una complementació entre l'estat i la societat civil. Més encara, és en l'àmbit de la societat civil on millor 
podem treballar per a recuperar el valor i la força per a transformar una realitat clarament injusta.

Una complementació no és una substitució. L'Estat continua sent el principal responsable del que és públic; per exemple, de garantir els drets socials i econòmics com ara la sanitat, el treball, la protecció social, la vivenda, etc. El paper de la societat civil no és recollir les restes del naufragi de l'estat social i convertir un dret ciutadà i, per tant, una obligació de l'Estat, en un tema de voluntarisme o altruisme. La funció de la societat civil és treballar colze amb colze amb les institucions polítiques, però cadascú ha de respectar les seues fronteres.

Recuperar la societat civil vol dir, per exemple, que també l'empresa és responsable de l'ocupació i del desenvolupament local; vol dir que l'atenció sanitària no només depèn de les polítiques públiques o de les lleis de sanitat, sinó també de la pràctica professional i del compromís dels hospitals per la qualitat; vol dir que el seguiment $i$ control de l'activitat política no és només tema dels parlaments i dels partits polítics, sinó també d'una ciutadania desperta que té en els moviments socials i en la nova galàxia mediàtica un gran poder de monitorització; vol dir que els mitjans de comunicació són alguna cosa més que l'expressió d'interessos econòmics o polítics; i un llarg etcètera.

Amb aquesta nova distribució de la responsabilitat, tenim un eix de coordenades des del qual pensar la crisi i les possibles solucions. Moralitzar la societat civil no vol dir altra cosa que empoderar les persones perquè puguen moure's per aquest eix de possibilitats, entre la seua participació com a professionals, com a ciutadans compromesos amb les seues institucions polítiques i com a membres actius i participatius en les diverses esferes de la societat civil. De mostrar el paper que té l'ètica en aquesta distribució se n'ocuparà el nostre darrer punt.

\section{L'ÈTICA EN EL DISSENY INSTITUCIONAL}

Si necessitem de la mediació institucional per a aconseguir molts dels nostres objectius morals, hem de parlar d'una ètica de les institucions com a part fonamental de tota ètica aplicada. L'objectiu és explicitar les condicions que fan possible tot acord institucional, és a dir, a reconstruir la infraestructura moral subjacent a aquest marc institucional de valors i regles. En resum, identificar i formular les bases morals de la confiança dipositada en les institucions.

La indignació que recorre avui els nostres carrers i la capacitat que tenim d'ofendre'ns assenyalen directament aquesta infraestructura moral. La gent s'indigna perquè sap, malgrat la manipulació informativa, que els qui ocupen els llocs de poder han incomplit les expectatives legítimes que havíem dipositat en 
ells. Això vol dir que sap ben bé què és pot esperar de les institucions, millor dit, què tenim dret a esperar de les institucions. Si les institucions i els dirigents ens han decebut és perquè coneixem els criteris morals que haurien d'haver definit la seua conducta, que han estat traïts, provocant la nostra indignació.

Per a identificar aquesta infraestructura moral, la metodologia que utilitzem és la d'una hermenèutica crítica que estudia, en cada esfera o pràctica social, en l'educació, la sanitat, la política, la defensa, etc., com és possible d'aconseguir la conformitat de tots els grups implicats i afectats. Hermenèutica perquè hem d'analitzar la lògica pròpia de cada pràctica per a entendre les regles de funcionament de la institució, per a mostrar les opcions i restriccions, els beneficis esperables, els deures i obligacions, les capacitats i forces, etc. No podem aplicar a una institució que pertany a una determinada pràctica social, l'estructura i funcionament d'una altra. Crítica perquè, dins de l'especificitat de cada institució, sempre hem de buscar les condicions que possibiliten l'acceptació lliure i voluntària de tots els membres.

Parlar de disseny pot parèixer una frivolitat, però es fàcil veure que no és el cas quan recordem que l'arrel llatina de dissenyar és designare, és a dir, quan aclarim que l'objectiu d'una ètica de les institucions és assenyalar els principis capaços de convertir-se en bones raons per a argumentar la moralitat o justícia de la institució. Des d'aquestes raons es formulen criteris normatius per a la possible intervenció institucional. Sempre en un treball interdisciplinari on l'ètica és sols una part en aquesta deliberació pública al voltant de les institucions.

Segur que pensareu que és tot molt bonic, però molt abstracte. Potser us quede més clar si deixem de parlar en general i ens centrem en una història de desgraciada actualitat.

La situació de les caixes d'estalvis és un bon exemple de com institucions econòmiques, que comptaven amb l'acord i el reconeixement social, poden desaparèixer, d'allò que hem anomenat vulnerabilitat institucional. Parlem d'una institució amb centenars d'anys de vida, de tal importància que va arribar a tindre una gran part de la intermediació financera i que, a més, estava caracteritzada per un fort compromís social. Potser tinga molt a veure amb aquest enfonsament la bombolla immobiliària, però estareu d'acord amb mi en buscar les raons en la entrada majoritària de representants polítics en els consells d'administració amb els criteris propis dels partits polítics. El dèficit de governança estava assegurat.

Tant la llei de 1985 com diverses sentències del Tribunal Constitucional, la composició del qual també depèn dels partits polítics, modificaren els òrgans de govern d'aquestes entitats, i van introduir-hi amb força la presència de les comunitats autònomes i dels representants polítics. De manera que les persones de reconegut prestigi en l'àmbit de la economia i les finances que la llei demanava, han acabat per ser els nomenats a dit pels partits. En comptes d'una gestió 
professional, sota la lògica econòmica de la rendibilitat i solvència, s'ha fet una gestió política de cara al govern corresponent, és a dir, d'instrument financer i social s'ha passat a instrument polític.

Si a la ingerència política li sumem l'absència de transparència i control, ens adonem que ja feia temps que les caixes es comportaven com autèntiques institucions suïcides. Al final d'aquesta història hem perdut un bon exemple d'una institució econòmica que havia sabut integrar el benefici social i l'econòmic, com molt bé sap aquesta Universitat. En definitiva, hem perdut un bon element de la societat civil.

En el cas de les caixes d'estalvis ja no podem fer-hi res, però sí aprendre'n les conseqüències de polititzar en comptes de moralitzar, de deixar que els polítics monopolitzen la vida pública, de no lluitar més fort per a participar en allò que ens afecta. Però, com ara veurem en un altre exemple, no n'hem aprés molt.

Pareix que, després de la sanitat i l'educació, li arriba l'hora a la universitat. $\mathrm{Hi}$ ha gent que pensa en un canvi institucional fort a les universitats, on un patronat, un consell executiu $i$ un senat serien les estructures bàsiques. La principal novetat: desapareixen les eleccions al si de la universitat, el rector o rectora seria nomenat per un patronat on, sorpresa, hi ha una majoria de polítics. Els estudiants i les estudiantes no hi tenen cap vot, només veu al senat. De nou, la intromissió de maquinària partidista pot trencar la lògica pròpia universitària que té, a tot el món i des de els inicis, en el principi d'autonomia el motor de funcionament. Els nostres representants polítics han de ser a la universitat, però el pes de les decisions ha de recaure en els propis implicats i afectats. Encara hi som a temps de parar aquest suïcidi institucional.

Hi ha, per descomptat, molt més exemples, però la conclusió és ben clara: o establim un debat, obert i públic, de com millorar moltes de les nostres institucions $\circ$ uns altres faran la feina sense argumentar res més que aplicar la regla de majories i la lògica partidista. En aquest debat és on té alguna cosa a dir una ètica institucional.

Un dels principis morals en els quals ens hem especialitzat a la nostra Universitat, i que intentem aplicar en diferents institucions, és el principi de responsabilitat. El principi per al disseny institucional es pot formular de manera breu com si fos un axioma que afirma que la confiança és directament proporcional a la capacitat que tenen les institucions per a donar raó del que fan o deixen de fer. És a dir, la comunicació de la responsabilitat no és, en cap moment, posterior, és part de la mateixa responsabilitat.

Aquest principi es basa en el principi de publicitat de Kant, en la idea senzilla que una decisió o acció que siga clarament injusta no suporta la publicitat. Com diu Kant: són injustes totes les accions que no poder fer-se públiques, mentre que les accions que necessiten de la publicitat per a aconseguir els seus 
objectius, és a dir, del coneixement i el consentiment dels altres, són justes. Ara no puc entrar en l'explicació d'aquestes paraules, només dir que parlem de transparència, però no sols de deixar passar la llum, sinó d'exigir la participació de tots els afectats per a demanar i controlar la informació. Responsabilitat com a la suma de transparència i de participació.

El treball de l'ètica amb les organitzacions concretes, siguen empresarials, sanitàries o universitàries, consisteix a transformar aquest principi moral en mecanismes de gestió com ara els codis d'ètica, les memòries de responsabilitat social, les auditories ètiques, etc. Són bons exemples de que l'ètica en les institucions es pot gestionar i que el resultat d'aqueixa gestió és un actiu tan important com ara la generació de confiança.

Bé, ja és hora de finalitzar. La pintada que m'ha servit d'excusa per a pensar aquesta lliçó no acaba amb la disjuntiva «Ètica o crisi». Desprès d'un punt i seguit, pregunta directament al viatger: "Tu què faràs?». Ens recorda que la responsabilitat sempre és compartida, per més distribuïda que estiga.

Des de la teoria ètica, ni tenim ni podem tindre la resposta, però sí que he volgut presentar algunes reflexions per a trobar-la. En aquesta lliçó m'he basat principalment en les idees de tres autors: Karl-Otto Apel, Amartya Sen i Adela Cortina. Els tres són doctors honoris causa d'aquesta Universitat, companys nostres del Claustre. A partir dels seus treballs, des de la filosofia i l'economia, podem definir un horitzó d'actuació que ens permeta orientar-nos a l'hora de pensar què hem de fer.

Dins d'aquest horitzó he volgut destacar la presència i importància de les nostres capacitats per a actuar moralment $\mathrm{i}$ crec que allò que hem de fer per a encarar la crisi és activar aquest poder. Per a aquest fi, la meua proposta és que hem de començar per participar al si de les organitzacions de la societat civil, si és possible sense delegacions ni representants. D'aquesta manera tindrem al nostre abast uns recursos no només eficaços, sinó també, és decisiu recordar-ho quan pensem en la motivació, gratificants. Per la senzilla raó que hem nascut per a ser actors i no simples espectadors de la nostra vida. 


\section{REFERÈNCIES}

ApEL, K.-O. (1988): Diskurs und Verantwortung, Suhrkamp, Frankfurt - (1986): Estudios Éticos, Alfa, Barcelona

Aranguren, J.L.L. (1994): Ética, Obras Completas, Trotta, Madrid

Aristóteles (1970): Ética a Nicómaco, Centro de Estudios políticos, Madrid

ConILL, J. (2004): Horizontes de economía ética, Tecnos, Madrid

CoRtina, A. (1993): Ética aplicada y democracia radical, Tecnos, Madrid

- (1998): Hasta un pueblo de demonios, Taurus, Madrid

- (2007): Ética de la razón cordial, Nobel, Oviedo

Cortina, A. i García-MarzÁ, D. (2003): Razón pública y éticas aplicadas, Tecnos, Madrid

GarcíA-MARZÁ, D. (2004): Ética empresarial: del diálogo a la Confianza, Trotta, Madrid

- (2012): "Kant's Principle of Publicity", Kant-Studien, 103, pp. 96-113

HaberMAS, J. (2000): Aclaraciones a la ética del discurso, Trotta, Madrid

HeGEl, G.W.F. (1988): Principios de Filosofía del Derecho, Edhasa, Barcelona

Kant, I. (1985): La paz perpetua, Tecnos, Madrid

NORTH, C. (1985): Instituciones, cambio institucional y desempeño Económico, FCE, México

Ortega i Gasset, J. (2004): Misión de la universidad, Obras completas, Madrid

Ostrom, E. (1990): Governing the Commons, Cambridge University Press

RAWLS, J. (1978): Teoría de la justicia, F.C.E., Madrid

SEN, A. (2000): Desarrollo y libertad, Planeta, Barcelona

- (2003): "Ética empresarial y desarrollo económico", en CortinA, A., (ed.),

Construir confianza, Trotta, Madrid

- (2010): La idea de la justicia, Santillana, Madrid

ZUBIRI, X. (1986): Sobre el hombre, Madrid, Alianza 


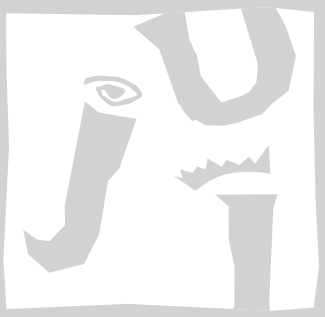

UNIVERSITAT JAUME•I 